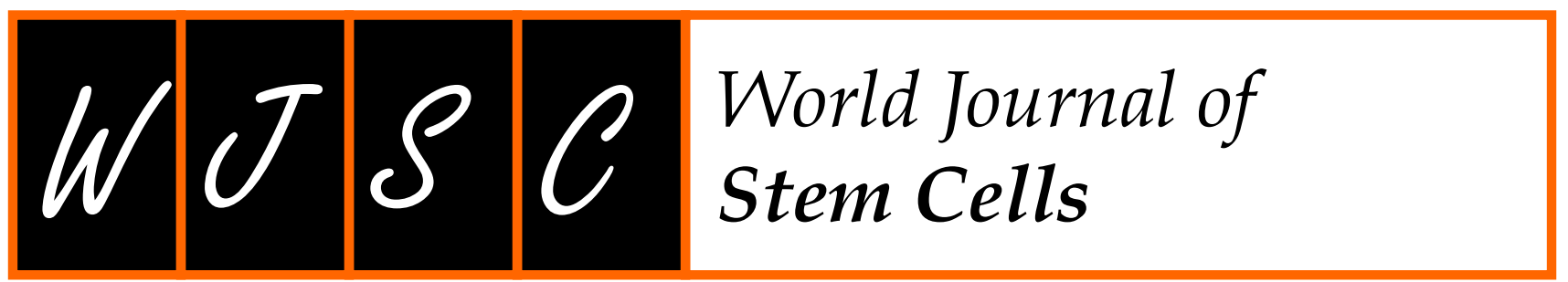

\title{
Effect of aging on behaviour of mesenchymal stem cells
}

\author{
Juan Antonio Fafián-Labora, Miriam Morente-López, María C Arufe
}

ORCID number: Juan Fafián-Labora (0000-0003-1510-8666); Miriam Morente-López

(0000-0001-8547-7489); María C Arufe (0000-0003-3725-0743).

Author contributions: All authors equally contributed to this paper with conception and design of the study, literature and analysis, drafting and critical revision and editing, and final approval of the final version.

Supported by Consellerí a de Cultura, Educación e Ordenación Universitaria, Xunta de Galicia (Spain), Fafián-Labora JA is recipient of a postdoctoral fellowship (ED481B 2017/117).

Conflict-of-interest statement: No potential conflicts of interest. No financial support.

Open-Access: This article is an open-access article which was selected by an in-house editor and fully peer-reviewed by external reviewers. It is distributed in accordance with the Creative Commons Attribution Non Commercial (CC BY-NC 4.0) license, which permits others to distribute, remix, adapt, build upon this work non-commercially, and license their derivative works on different terms, provided the original work is properly cited and the use is non-commercial. See: http://creativecommons.org/licen ses/by-nc/4.0/

Manuscript source: Invited manuscript

Received: February 23, 2019

Peer-review started: February 26, 2019

First decision: March 15, 2019
Juan Antonio Fafián-Labora, Miriam Morente-López, María C Arufe, Grupo de Terapia Celular y Medicina Regenerativa, Departamento de Fisioterapia, Ciencias Biomédicas y Medicina, Universidade da Coruña, A Coruña 15006, Spain

Corresponding author: María C Arufe, PhD, Professor, Grupo de Terapia Celular y Medicina Regenerativa, Departamento de Fisioterapia, Ciencias Biomédicas y Medicina, Universidade da Coruña, Facultad de Ciencias de la Salud, Campus de Oza, INIBIC-CHUAC, A Coruña 15006, Spain.maria.arufe@udc.es

Telephone: +34-981-167399

Fax: +34-981-167398

\section{Abstract}

Organs whose source is the mesoderm lineage contain a subpopulation of stem cells that are able to differentiate among mesodermal derivatives (chondrocytes, osteocytes, adipocytes). This subpopulation of adult stem cells, called "mesenchymal stem cells" or "mesenchymal stromal cells (MSCs)", contributes directly to the homeostatic maintenance of their organs; hence, their senescence could be very deleterious for human bodily functions. MSCs are easily isolated and amenable their expansion in vitro because of the research demanding to test them in many diverse clinical indications. All of these works are shown by the rapidly expanding literature that includes many in vivo animal models. We do not have an in-depth understanding of mechanisms that induce cellular senescence, and to further clarify the consequences of the senescence process in MSCs, some hints may be derived from the study of cellular behaviour in vivo and in vitro, autophagy, mitochondrial stress and exosomal activity. In this particular work, we decided to review these biological features in the literature on MSC senescence over the last three years.

Key words: Mesenchymal stem cells; Aging; Autophagy; Mitochondrial stress; Extracellular vesicles

CThe Author(s) 2019. Published by Baishideng Publishing Group Inc. All rights reserved.

Core tip: The point of interest of this work is the behaviour of the mesenchymal stromal cell (MSC) through aging, which can occur over time in the culture (in vitro) or in its own physiological niche (in vivo). This review defines the current knowledge published in the MSC field that focuses mainly on the mechanisms that influence its senescence in vivo and in vitro in the last three years. Three cellular mechanisms are of special importance in this review, since they can decisively influence the behaviour of MSC in aging, such as autophagy, oxidative stress and the production of extracellular vesicles. 
Revised: March 29, 2019

Accepted: May 6, 2019

Article in press: May 6, 2019

Published online: June 26, 2019

P-Reviewer: Chivu-Economescu M, Grawish ME, Jun YM, Liu L, Saeki K, Shawcross SG, Yao CL

S-Editor: Ji FF

L-Editor: A

E-Editor: Wu YXJ
Citation: Fafián-Labora JA, Morente-López M, Arufe MC. Effect of aging on behaviour of mesenchymal stem cells. World J Stem Cells 2019; 11(6): 337-346

URL: https://www.wjgnet.com/1948-0210/full/v11/i6/337.htm

DOI: https://dx.doi.org/10.4252/wjsc.v11.i6.337

\section{INTRODUCTION}

Mesenchymal stem cells (MSCs) are located in specific areas of tissues, called "niches", and are characterized as being in a state of relative quietness, from which they can exit under the proper conditions to obtain the proliferative potential necessary for tissue regeneration ${ }^{[1]}$. MSCs have sustained interest among researchers by contributing to tissue homeostasis and modulating inflammatory response, all activities accomplished primarily by the secretion of cytokines and growth factors, because their paracrine action is the main mechanism explaining their effects, regardless of source.

Senescence is defined as a mechanism for limiting the regenerative potential of stem cells which is involved with metabolic changes in the oxidative state of the cell, this process that has been also linked to mitochondrial fission and fusion events could indicate association between mitochondrial dynamics and senescence ${ }^{[2]}$. Furthermore, senescence-associated phenotypes are characterized by increased activity of SA- $\beta$-gal, altered autophagy, and increased G1 cell cycle arrest, reactive oxygen species (ROS) production and expression of p53 and p $21^{[3]}$. It is now evident that senescent cells secrete dozens of molecules, for which the terms "senescence-associated secretory phenotype (SASP)" and "senescence-messaging secretome (SMS) factors" have been proposed. Premature aging produced by overexpression of mutant LMNA called progerin in the rare disease Hutchinson-Gilford Progeria Syndrome is linked to upregulation of SASP by GATA4-dependent regulation via MCP-1 in human MSC aging ${ }^{[4]}$. The secreted factors contribute to cellular proliferative arrest through autocrine/paracrine pathways as well as in vivo and in vitro ${ }^{[5-8]}$. SMS factors released by senescent cells play a key role in cellular senescence and physiological aging by activation of cytoplasmic signalling circuitry, so SMS factors secreted in conditioned medium of senescent MSCs induce a paracrine mechanism of premature senescence in young cells ${ }^{[9]}$.

The milestone in MSC investigation will be discovering senescence markers to determine the quality of the in vitro cells for cell-based therapies. Madsen et a $\mathbf{l}^{[10]}$ have proposed TRAIL receptor CD264 as the first cellular senescence mesenchymal marker in bone marrow-derived MSCs, because it has the same expression profile of $\mathrm{p} 21$ during culture passage and it is not linked to $\operatorname{sex}^{[10]}$. On the other hand, it is a good approach to identify immunogenic markers from age tissue sources, and the first study was developed by Amati et al ${ }^{[11]}$, who proposed the angiotensin-converting enzyme CD143 as a marker expressed in adult tissue sources from the screening using bone marrow- and cord blood-derived MSCs (Figure 1B).

\section{MSC's' BEHAVIOUR IN VITRO}

After long-term expansion, the phenotype of MSCs keeps stable and cells present similar immunogenic properties to lower passage cells. However, their immunosuppressive properties are reduced ${ }^{[12]}$. One of the drawbacks of MSCs is the decline in their self-renewal capacity with increased donor age (Figure 1A) and in vitro expansion $^{[13-18]}$ (Figure 1B). However, by increasing the number of umbilical cord veinMSC passages, immunosuppressive effects were promoted as a result of the greater purity of the MSCs and their major compatibility with culture conditions ${ }^{[19]}$. These results reveal the different implications of the application of high passage MSCs in the clinic, it would help increase their production for therapeutic uses but might interfere with their efficacy. The self-renewal of MSCs decrease is caused by shor-tening telomeres in aged MSCs ${ }^{[14]}$ and this was also demonstrated when overexpression of hTERT bypassed a replicative senescence in hBM-MSCs ${ }^{[20]}$. Kouroupis et al ${ }^{[21]}$ have reported that the number of CD146 ${ }^{+}$UC-derived MSCs decreased with the in vitro age and this is associated with the telomere length. This year, it was discovered that epigenetic changes are implicated in the maintenance of stem cell properties of MSCs, demonstrating that expression of the pluripotency marker Oct4 keeps self-renewal and reverse aging in human hair follicle derived-MSCs through the inhibition of p21 


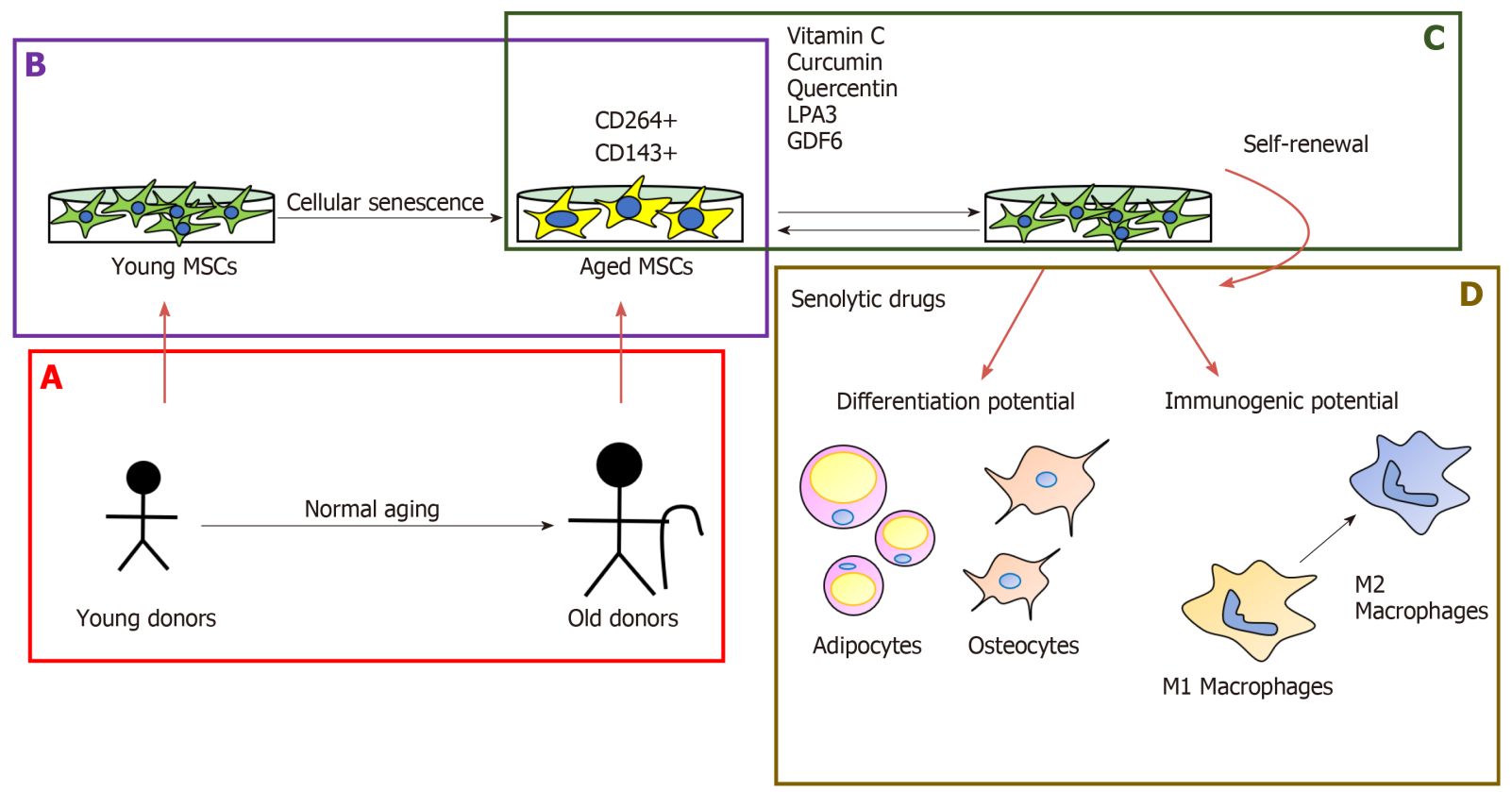

Figure 1 Effect of aging on self-renewal, differentiation and immunogenic potential from mesenchymal stem cells. A, B: Stem cell properties of mesenchymal stem cells (MSCs) are limited by age donor (A), and their long-term in vitro culture (B); C: Some new agents can ameliorate the effect of cellular senescence on the therapeutic capacity of MSCs; D: Treatment with senolytic drugs affects the behaviour of MSCs. MSCs: Mesenchymal stem cells; LPA: Lysophosphatidic acid.

by DNA methyltransferases ${ }^{[2]}$.

Non-coding RNA can play a role in the cellular senescence in MSCs, though the interfering lincRNA-p21 expression might allow the rejuvenation of aged BM-MSCs from C57BL/6 mice via the Wnt/b-catenin signalling pathway ${ }^{[23]}$. Rn7SK is a conserved small nuclear non-coding RNA, which is overexpressed in senescent adipose tissue-derived MSCs. So, it is directly involved in the decrease of osteogenic differentiation and proliferation ${ }^{[24]}$.

There is an increase in the number of studies about the effect of natural-origin regulators that prevent or ameliorate cellular senescence in MSCs. Vitamin C also has the potential to re-establish the activity of telomerase reverse transcriptase (TERT) in bone marrow-derived MSCs from senescence-accelerated mouse prone 6 (SAMP6) mice $^{[25]}$. Curcumin improves the proliferation of aged rat adipose tissue-derived MSCs through TERT gene expression ${ }^{[26]}$ (Figure 1C). Another option for treating age-related diseases is the use of senolytic drugs, which eliminate target senescent cells and rejuvenate tissues ${ }^{[27]}$. Grezella et al ${ }^{[28]}$ have studied the impact of these drugs on human MSCs, such as ABT-263, quercetin, danazol and nicotinamide ribose, which don't have a positive effect on MSCs because they produce changes in the SASP of human femoral bone marrow MSCs. However, Geng et a ${ }^{[29]}$ have proposed quercetin as a geroprotective compound for human MSCs from Werner syndrome. Because it reestablishes the differentiation potential and self-renewal through its antioxidant capacity and growth differentiation factor 6 , secreted by young MSCs, it can restore the osteogenic capacity of MSCs from elderly donors ${ }^{[2,30]}$ (Figure 1D).

Human bone marrow MSCs from young donors have a better monocyte polarization capacity than MSCs from old donors ${ }^{[31]}$. Non-senescent MSCs secrete some bioactive factors, which can ameliorate the replicative senescence through enhanced cell proliferation and osteogenic differentiation potential in prolonged in vitro culture $^{[32]}$. Human umbilical cord blood MSCs stimulate the rejuvenation function in human $\operatorname{skin}^{[33]}$. Lysophosphatidic acid (LPA) is a bioactive small glycerophospholipid derived from cytoplasm that promotes cell proliferation, survival and migration ${ }^{[34]}$. Complementing those results, Kanehira et al ${ }^{[35]}$ have stated that two components of these acids (LPA1 and 3) regulate cellular senescence in MSCs positively and negatively, respectively.

\section{MSCs' BEHAVIOUR IN VIVO}

MSCs isolated from the term umbilical cord vein have stronger immunomodulatory capacity than preterm ones. Increased immunological maturity of term umbilical cord 
vein MSCs may be the explanation for that ${ }^{[19]}$.

In vivo senescence of MSCs is associated with bone-related disease because the cells lost the osteogenic capacity. In the last year, the number of studies based on gene therapy has increased with a view to improving the stem cell properties in the development of cell-based therapies. Non-coding RNA like miR-1292 was proposed as a senescence regulator in human adipose-derived MSCs and delay bone formation in vivo by targeting FZD4 via the Wnt/b-catenin pathway. It is a good target for the prevention and treatment of osteoporosis ${ }^{[36]}$. The loss of the in vivo osteogenesis potential of aged bone marrow MSCs is mediated by p53 through the miR-17 pathway ${ }^{[37]}$. In cardiovascular disease, it was found that overexpression of miR-10a in aged human bone marrow MCs activates AKT and improves the angiogenesis in ischaemic mouse hearts ${ }^{[38]}$. The overexpression of FOXQ1 in UC-derived MSCs regulates the migration and anti-senescence effects ${ }^{[30]}$. SATB2-modified bone marrowderived MSCs significantly ameliorate ovariectomy-induced alveolar bone loss in vivo ${ }^{[40]}$.

In the last few years, the MSCs from human-induced pluripotent stem cells have had low oncogenic potential and strong immune capacity to regulate $\mathrm{T}$ cells ${ }^{[41]}$. They modulate CD4 and CD8 cells and lead the upregulation of immune genes and downregulation of c-myc and DNA replicative pathways ${ }^{[2]}$.

\section{AUTOPHAGY IN MSCs}

Autophagy increases when MSCs enter the replicative aging state, and p53 contributes an important role in the upregulation of autophagy in this condition ${ }^{[43]}$. In contrast, suppression of the p53 transcriptional activity produced strong cell death of $\mathrm{H}_{2} \mathrm{O}_{2}$-treated MSCs through autophagy induction ${ }^{[44]}$. Autophagy is playing an important role in the mammalian stress response because can be modulated by several ways through hypoxia induced stress in different organelles. Autophagy is deeply linked to senescence, and in some experimental models, the onset of senescence is dependent on a preliminary autophagy induction: For instance, the downregulation of IGF-1 protects senescence MSCs from hypoxic condition by growing the level of autophagy, thereby allowing the survival of senescence bone marrow MSCs after myocardial infarction transplantation ${ }^{[45]}$ (Figure 2). Brunk and Termal ${ }^{[46]}$ presented the theory of aging which consisted in accumulation of damage in mitochondrial-lysosomal axis as a result of imperfect autophagocytosis during aging in tissue with limited turnover, and this has remained valid until now, when reversible quiescence is the normal stem cell state throughout life-adds ${ }^{[46-48]}$. In the opposite, in other contexts the decrease of autophagy provokes senescence, as shown in several types of MSC acute senescence which the autophagy flux is heavily imbalanced, indicating the autophagy counteracts damaged processes, and its decline produces senescence ${ }^{[49]}$. Reconciling these opposite events would be possible by speculating that MSCs try to lead with stress by inducing autophagy that removes damaged components; in this scenario, autophagy would protect from aging and its malfunction might trigger senescence. However, if autophagy cannot counteract stress-induced damage, it could induce senescence. Hyperglycaemia has been reported to MSC senescence ${ }^{[50]}$. Chang et $\mathrm{l}^{[51]}$ researched the role of high-glucoseinduced autophagy in MSC senescence publishing that high glucose increased autophagosome formation, which was linked with the development of senescence process in the cell. 3-methyladenine treatment in MSCs prevented their senescence because of increasing apoptosis. However, $\mathrm{N}$-acetylcysteine or Diphenyleneiodonium, an inhibitor of NADPH oxidase, treatments were effective blocking autophagy and senescence through preventing high-glucose-induced autophag $y^{[51]}$.

All these results indicate that hyperglycaemia induces MSC aging and an increase of inflammation through oxidant-mediated autophagy, contributing to MSCs' niche dysfunction. On the other hand, methionine restriction may mediate its anti-aging effects through the induction of macroautophagy/autophagy as well ${ }^{[52]}$.

MSCs are extremely sensitive and very low doses of radiation can induce senescence because of impairing autophagy and their limited DNA repair capacity ${ }^{[53]}$. Activation of autophagy restored bone loss in aged mice, suggesting that autophagy has a key role in the aging of MSCs, and an increase of autophagy can partially reverse this senescence process and might represent a new potential therapy for clinically treating age-related bone loss ${ }^{[5,55]}$.

MSCs in lysosomal storage disorders (LDS), which impair lysosomal homeostasis, are prone to apoptosis and senescence due to impaired autophagy and DNA repair capacity ${ }^{[56]}$. Recently, a study showed that novel small molecules can selectively and sensitively respond to acidic $\mathrm{pH}$, promoting lysosomal acidification and inhibiting 


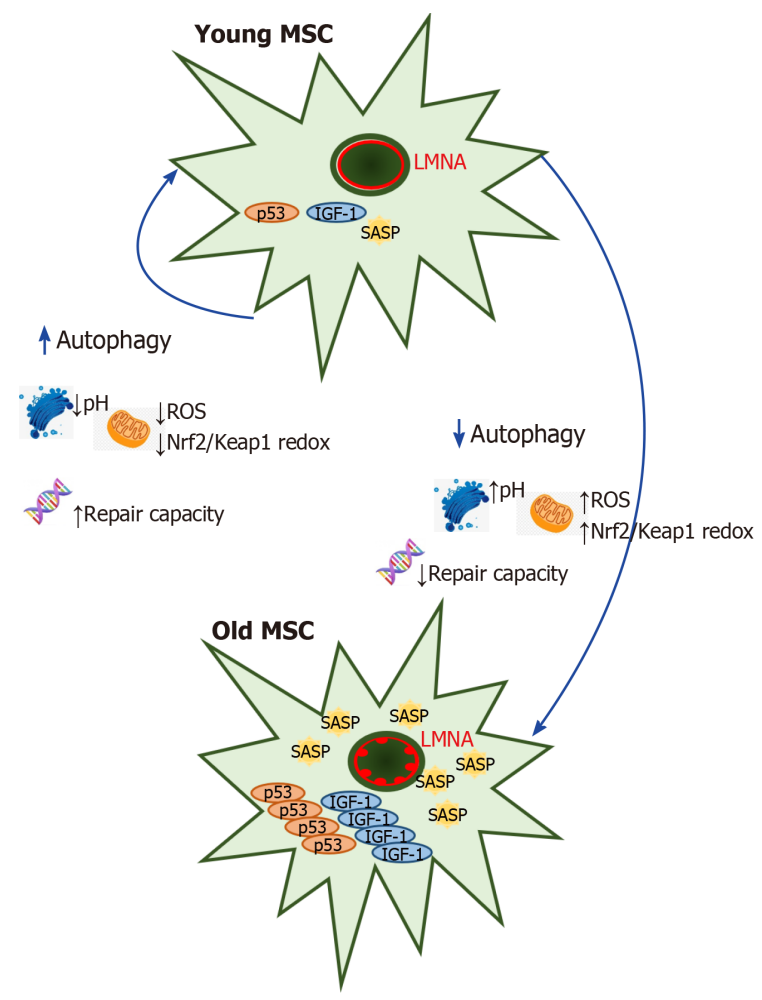

Figure 2 Autophagy influences senescence in mesenchymal stem cells. The self-renewal potential of young mesenchymal stem cells (MSCs) is influenced by their autophagy capacity to regulate the good levels of oncogenic factors like p53 and inflammatory signals like senescence-associated secretory phenotype and IGF-1, which produces overexpression of reactive oxygen species in the mitochondria, accumulation of mutations at DNA levels and acidification in the lisosomal apparatus together with an increase of LMNA in the nucleus. When autophagy is downregulated by the pathologic process, young MSCs become old MSCs in an accelerated way, losing their selfrenewal capacity. MSC: Mesenchymal stem cell; ROS: Reactive oxygen species.

senescence in MSCs through autophagy ${ }^{[57]}$. Decreased autophagy is one of the mechanisms underlying aging. Yang et a ${ }^{[58]}$ demonstrated that reducing autophagy decreases the hypoxia tolerance of senescent MSCs and Yun et al ${ }^{[59]}$ demonstrated that high p-Cresol serum concentration caused by chronic kidney failure produced cell senescence through the induction of autophagy response and could be potentially rescued by the administration of melatonin through inhibiting mTOR-dependent autophagy ${ }^{[58,59]}$. Maintaining optimal levels of autophagy might serve as a new strategy for using MSC transplantation.

\section{MITOCHONDRIAL STRESS IN MSCs}

Oxidative stress is characterized by unregulated production and/or the elimination of reactive oxygen and nitrogen species. The main ROS generation sites, under physiological conditions, are found within the electron transport chain in the mitochondria. MSC differentiation processes ROS are mainly generated from mitochondrial complexes I and III and the NOX4 isoform of NADPH oxidase ${ }^{[60]}$. The deregulation of ROS generation by $\mathrm{CI}$ and CIII can be an important factor for aging and it has been shown that an increase in ROS levels and the resulting oxidative damage are highly correlated with aging ${ }^{[61-63]}$. Deschênes-Simard et al ${ }^{[64]}$ linked the bypassing of senescence in premalignant lesions to a decrease of differentiation, an increase of self-renewal potential and an increase in their dependence of mitochondrial functions. Aged adipose tissue-derived MSCs and their adipogenic differentiation are decreased by downregulation of Sirtuin 1 through miR-34a ${ }^{[65]}$. Another component, Sirtuin 3 (SIRT3), protects aged human MSCs against oxidative stress through positive regulation of MnSOD and CAT via activation of FoxO3a ${ }^{[39]}$. Huang et al $^{[66]}$ have reported that the reduction of ERRalpha-directed mitochondrial glutaminase expression suppresses the osteogenic differentiation in aged mice MSCs. Melatonin reduces endoplasmic reticulum stress (ERS) in the liver and several diseases in the nervous system and lung. It is involved in maintaining stemness during long-time in vitro expansion ${ }^{[67]}$. Yun et al ${ }^{[59]}$ demonstrated that MSCs from rats 
with chronic kidney disease exhibited greater senescence induced by oxidative stress than normal MSCs, whereas when treated with melatonin, it protected them from $\mathrm{H}_{2} \mathrm{O}_{2}$ and excessive associated senescence. Fang et al ${ }^{[68]}$ have reported that it prevents senescence in canine adipose-derived MSCs through activation of Nrf2 with the inhibition of NFK beta and ERS. L-carnitine is a transport of long-chain fatty acids into the mitochondria for degradation by beta-oxidation and it has the potential to increase telomerase activity by changing the methylation status of the human TERT promotor in aged adipose tissue-derived MSCs ${ }^{[69,70]}$. Wang et al ${ }^{[57]}$ postulate that treatment with curcumin gives bone marrow MSCs the ability to survive and this could be attributed to their protection in the mitochondrial function, destabilization of HIF-1a and the activation of the Epac1-Akt signalling pathway. Therefore, they suggest that curcumin influences the preconditioning of MSCs to facilitate cell therapy in the treatment of tissue repair. Oh et al ${ }^{[7]}$ propose the role of $17 \beta$-estradiol (E2) as a potential target to prevent or treat metabolic disorders in the production of reactive mitochondrial oxygen species induced by glucose (mtROS) through signalling mediated by the oestrogen receptor in MSCs from umbilical cord blood in vitro, suggesting that E2 serves as a potent antioxidant. Denu et al ${ }^{[72]}$ propose that SIRT3 is a sirtuin involved in aging (it is the main mitochondrial deacetylase) that decreases mitochondrial ROS and promotes an efficient oxidative metabolism. It has been shown that SIRT3 reduces the decrease in function and senescence associated with age in multiple cell types. Then, the increase in nuclear translocation of Nrf2 triggered the positive regulation of SIRT3 and the activation of manganese superoxide dismutase (MnSOD), which plays an important role in the decrease of mtROS levels. During MSC expansion in vitro, they experience a replicative senescence that compromises their immunomodulatory and differentiation functions due to increased ROS and oxidative stress in aged stem cells. MSCs accelerate aging and inhibit differentiation in adipocytes and osteoblasts because of the elimination of SIRT3, and because the overexpression of SIRT3 in the last step of the MSC restores its capacity for differentiation and reduces oxidative stress ${ }^{[73]}$. The study by Yao et a ${ }^{[74]}$ attempts to demonstrate that human umbilical cord MSC-derived EVs carrying MnSOD could alleviate oxidative stress in liver tissue in vivo.

Oxidative stress is a key process in the induction of cellular senescence according to several studies ${ }^{[75-77]}$. Afterwards low-grade chronic inflammation during aging and associated pathologies can lead to oxidative stress and rupture of the cells that cause senescence. According to Platas et al $l^{[78]}$, chronic oxidative stress related to aging or mechanical stress can cause cellular senescence in joint tissues and age-related alterations in the differentiation and function of MSCs.

\section{MSC-DERIVED EXTRACELLULAR VESICLES}

Exosomes and microvesicles are small vesicles included in the term extracellular vesicles (EVs). Recently, it is unravel their function in cell-to-cell communication and their capacity for transporting proteins, signalling lipids and miRNAs which are relieved to target cells via endocytosis and membrane fusion. Lately, MSC-derived EVs are being studied for their role in MSC-based cellular therapy. These VEs have the capacity to alter cell or tissue metabolism at short or long distances in the organism. The EVs are influencing tissue responses to infection, injury and disease. MSC-derived EVs could be used for cell-free therapies. However, these therapies might be applied in clinic when parameters as quality, reproducibility and potency of their production can be controlled. In addition, it must be taken into account the MSCderived EV content is not static, they are produced by MSCs and they are influenced by specific MSC's niche. So, MSC-derived EVs are altered when MSCs are co-cultured with different types of cells in vitro or with tumour microenvironment in vivo[79,80]. It has been demonstrated that MSCs can induce tumour growth, and MSC-derived EVs can be very important in the tumour microenvironment transferring information between cells along disease's development. There are some findings supporting a new mechanism, suggesting the contribution of these MSC-derived EVs to tumour growth ${ }^{[81]}$. So, EVs secreted by MSCs might have therapeutic effects on the reconstruction process through promoting the cell cycle and inhibiting cell apoptosis, as happens in vaginal epithelium ${ }^{[82]}$.

Articles focused on a murine model have shown that a brief interaction of old MSCs with young MSC-derived Evs rejuvenated them and restored their functionality via inter-cellular communication. These EVs contained autophagy-related mRNAs through inhibition of AKT in aged MSCs increased the levels of autophagy-related mRNAs in their EVs ${ }^{[83]}$. MSC-derived EVs are also involved in the transport of antiimmunoinflammatory markers aging depending, confirming variations with aging of 
Toll-like receptor 4 pathway activation in rat bone marrow MSCs and containing proinflammatory miRNAs (miR-21, miR-155, miR-146 and miR-21) in their MSC-derived $\mathrm{EVS}^{[13]}$. Surprisingly, recent experiments show that the self-renewal power of these EVs is even better than that of the young MSCs. It has been demonstrated that such ex vivo self-renewal from old MSCs could increase the donor cohort improving efficacy in transplantation therapies ${ }^{[84]}$.

\section{CONCLUSION}

Aging affects the behaviour of MSCs in different ways depending on several factors, such as their status, source and pathological process. MSCs in vitro go into senescence earlier than in vivo and the pathological process stimulates their senescence in vivo. Despite this, or perhaps because of it, MSCs are an excellent tool to keep exploring in cellular therapy and to study senescence both in vivo and in vitro and their versatility seems to be extensively to their derived EVs.

\section{REFERENCES}

1 Rando TA. Stem cells, ageing and the quest for immortality. Nature 2006; 441: 1080-1086 [PMID: 16810243 DOI: 10.1038/nature04958]

2 Stab BR 2nd, Martinez L, Grismaldo A, Lerma A, Gutiérrez ML, Barrera LA, Sutachan JJ, Albarracín SL. Mitochondrial Functional Changes Characterization in Young and Senescent Human Adipose Derived MSCs. Front Aging Neurosci 2016; 8: 299 [PMID: 28018212 DOI: 10.3389/fnagi.2016.00299]

3 Zhang M, Du Y, Lu R, Shu Y, Zhao W, Li Z, Zhang Y, Liu R, Yang T, Luo S, Gao M, Zhang Y, Zhang G, Liu J, Lu Y. Cholesterol Retards Senescence in Bone Marrow Mesenchymal Stem Cells by Modulating Autophagy and ROS/p53/p21 Cip1/Waf1 Pathway. Oxid Med Cell Longev 2016; 2016: 7524308 [PMID: 27703600 DOI: 10.1155/2016/7524308]

4 Lee JY, Yu KR, Lee BC, Kang I, Kim JJ, Jung EJ, Kim HS, Seo Y, Choi SW, Kang KS. GATA4dependent regulation of the secretory phenotype via MCP-1 underlies lamin A-mediated human mesenchymal stem cell aging. Exp Mol Med 2018; 50: 63 [PMID: 29760459 DOI: 10.1038/s12276-018-0092-3]

5 Özcan S, Alessio N, Acar MB, Toprak G, Gönen ZB, Peluso G, Galderisi U. Myeloma cells can corrupt senescent mesenchymal stromal cells and impair their anti-tumor activity. Oncotarget 2015 ; 6: 3948239492 [PMID: 26498687 DOI: 10.18632/oncotarget.5430]

6 Kim HN, Chang J, Shao L, Han L, Iyer S, Manolagas SC, O'Brien CA, Jilka RL, Zhou D, Almeida M. DNA damage and senescence in osteoprogenitors expressing Osx 1 may cause their decrease with age. Aging Cell 2017; 16: 693-703 [PMID: 28401730 DOI: 10.1111/acel.12597]

$7 \quad$ Lazzarini R, Nicolai M, Pirani V, Mariotti C, Di Primio R. Effects of senescent secretory phenotype acquisition on human retinal pigment epithelial stem cells. Aging (Albany NY) 2018; 10: 3173-3184 [PMID: 30444724 DOI: 10.18632/aging.101624]

8 Severino V, Alessio N, Farina A, Sandomenico A, Cipollaro M, Peluso G, Galderisi U, Chambery A. Insulin-like growth factor binding proteins 4 and 7 released by senescent cells promote premature senescence in mesenchymal stem cells. Cell Death Dis 2013; 4: e911 [PMID: 24201810 DOI: 10.1038/cddis.2013.445]

9 Vassilieva IO, Reshetnikova GF, Shatrova AN, Tsupkina NV, Kharchenko MV, Alekseenko LL, Nikolsky NN, Burova EB. Senescence-messaging secretome factors trigger premature senescence in human endometrium-derived stem cells. Biochem Biophys Res Commun 2018; 496: 1162-1168 [PMID: 29397942 DOI: 10.1016/j.bbrc.2018.01.163]

10 Madsen SD, Russell KC, Tucker HA, Glowacki J, Bunnell BA, O'Connor KC. Decoy TRAIL receptor CD264: a cell surface marker of cellular aging for human bone marrow-derived mesenchymal stem cells. Stem Cell Res Ther 2017; 8: 201 [PMID: 28962588 DOI: 10.1186/s13287-017-0649-4]

11 Amati E, Perbellini O, Rotta G, Bernardi M, Chieregato K, Sella S, Rodeghiero F, Ruggeri M, Astori G. High-throughput immunophenotypic characterization of bone marrow- and cord blood-derived mesenchymal stromal cells reveals common and differentially expressed markers: identification of angiotensin-converting enzyme (CD143) as a marker differentially expressed between adult and perinatal tissue sources. Stem Cell Res Ther 2018; 9: 10 [PMID: 29338788 DOI: 10.1186/s13287-017-0755-3]

12 de Witte SFH, Lambert EE, Merino A, Strini T, Douben HJCW, O'Flynn L, Elliman SJ, de Klein AJEMM, Newsome PN, Baan CC, Hoogduijn MJ. Aging of bone marrow- and umbilical cord-derived mesenchymal stromal cells during expansion. Cytotherapy 2017; 19: 798-807 [PMID: 28462821 DOI: 10.1016/j.jcyt.2017.03.071]

13 Fafián-Labora J, Lesende-Rodriguez I, Fernández-Pernas P, Sangiao-Alvarellos S, Monserrat L, Arntz OJ, van de Loo FJ, Mateos J, Arufe MC. Effect of age on pro-inflammatory miRNAs contained in mesenchymal stem cell-derived extracellular vesicles. Sci Rep 2017; 7: 43923 [PMID: 28262816 DOI: 10.1038/srep43923]

14 Ganguly P, El-Jawhari JJ, Giannoudis PV, Burska AN, Ponchel F, Jones EA. Age-related Changes in Bone Marrow Mesenchymal Stromal Cells: A Potential Impact on Osteoporosis and Osteoarthritis Development. Cell Transplant 2017; 26: 1520-1529 [PMID: 29113463 DOI: 10.1177/0963689717721201]

15 Ucer S, Iyer S, Kim HN, Han L, Rutlen C, Allison K, Thostenson JD, de Cabo R, Jilka RL, O'Brien C, Almeida M, Manolagas SC. The Effects of Aging and Sex Steroid Deficiency on the Murine Skeleton Are Independent and Mechanistically Distinct. J Bone Miner Res 2017; 32: 560-574 [PMID: 27714847 DOI: 10.1002/jbmr.3014]

16 Xing Y, Zhang Y, Wu X, Zhao B, Ji Y, Xu X. A comprehensive study on donor-matched comparisons of three types of mesenchymal stem cells-containing cells from human dental tissue. J Periodontal Res 2019; 54: 286-299 [PMID: 30474138 DOI: 10.1111/jre.12630] 
17 Fafián-Labora J, Fernández-Pernas P, Fuentes I, De Toro J, Oreiro N, Sangiao-Alvarellos S, Mateos J, Arufe MC. Influence of age on rat bone-marrow mesenchymal stem cells potential. Sci Rep 2015; 5: 16765 [PMID: 26581954 DOI: 10.1038/srep16765]

18 LeBlon CE, Casey ME, Fodor CR, Zhang T, Zhang X, Jedlicka SS. Correlation between in vitro expansion-related cell stiffening and differentiation potential of human mesenchymal stem cells. Differentiation 2015; 90: 1-15 [PMID: 26381795 DOI: 10.1016/j.diff.2015.08.002]

19 Abolhasani M, Rezaee MA, Mohammadi M, Ghadimi T, Mohammadi M, Rahmani MR. Immunomodulatory properties of umbilical cord vein mesenchymal stromal cells influenced by gestational age and in vitro expansion. Immunol Lett 2018; 194: 62-68 [PMID: 29175314 DOI: 10.1016/j.imlet.2017.11.008]

20 Twine NA, Harkness L, Adjaye J, Aldahmash A, Wilkins MR, Kassem M. Molecular Phenotyping of Telomerized Human Bone Marrow Skeletal Stem Cells Reveals a Genetic Program of Enhanced Proliferation and Maintenance of Differentiation Responses. JBMR Plus 2018; 2: 257-267 [PMID: 30283907 DOI: 10.1002/jbm4.10050]

21 Kouroupis D, Churchman SM, McGonagle D, Jones EA. The assessment of CD146-based cell sorting and telomere length analysis for establishing the identity of mesenchymal stem cells in human umbilical cord. F1000Res 2014; 3: 126 [PMID: 25232467 DOI: 10.12688/f1000research.4260.2]

22 Lu Y, Qu H, Qi D, Xu W, Liu S, Jin X, Song P, Guo Y, Jia Y, Wang X, Li H, Li Y, Quan C. OCT4 maintains self-renewal and reverses senescence in human hair follicle mesenchymal stem cells through the downregulation of p21 by DNA methyltransferases. Stem Cell Res Ther 2019; 10: 28 [PMID: 30646941 DOI: 10.1186/s13287-018-1120-x]

23 Chen Y, Wei G, Xia H, Yu H, Tang Q, Bi F. Down regulation of lincRNA-p21 contributes to gastric cancer development through Hippo-independent activation of YAP. Oncotarget 2017; 8: 63813-63824 [PMID: 28969031 DOI: 10.18632/oncotarget.19130]

24 Musavi M, Kohram F, Abasi M, Bolandi Z, Ajoudanian M, Mohammadi-Yeganeh S, Hashemi SM, Sharifi K, Fathi HR, Ghanbarian H. Rn7SK small nuclear RNA is involved in cellular senescence. $J$ Cell Physiol 2019 [PMID: 30637716 DOI: 10.1002/jcp.28119]

25 Monacelli F, Acquarone E, Giannotti C, Borghi R, Nencioni A. Vitamin C, Aging and Alzheimer's Disease. Nutrients 2017; 9: pii: E670 [PMID: 28654021 DOI: 10.3390/nu9070670]

26 Pirmoradi S, Fathi E, Farahzadi R, Pilehvar-Soltanahmadi Y, Zarghami N. Curcumin Affects Adipose Tissue-Derived Mesenchymal Stem Cell Aging Through TERT Gene Expression. Drug Res (Stuttg) 2018; 68: 213-221 [PMID: 29017189 DOI: 10.1055/s-0043-119635]

27 Baar MP, Brandt RMC, Putavet DA, Klein JDD, Derks KWJ, Bourgeois BRM, Stryeck S, Rijksen Y, van Willigenburg H, Feijtel DA, van der Pluijm I, Essers J, van Cappellen WA, van IJcken WF, Houtsmuller AB, Pothof J, de Bruin RWF, Madl T, Hoeijmakers JHJ, Campisi J, de Keizer PLJ. Targeted Apoptosis of Senescent Cells Restores Tissue Homeostasis in Response to Chemotoxicity and Aging. Cell 2017; 169: 132-147.e16 [PMID: 28340339 DOI: 10.1016/j.cell.2017.02.031]

28 Grezella C, Fernandez-Rebollo E, Franzen J, Ventura Ferreira MS, Beier F, Wagner W. Effects of senolytic drugs on human mesenchymal stromal cells. Stem Cell Res Ther 2018; 9: 108 [PMID: 29669575 DOI: 10.1186/s13287-018-0857-6]

29 Geng L, Liu Z, Zhang W, Li W, Wu Z, Wang W, Ren R, Su Y, Wang P, Sun L, Ju Z, Chan P, Song M, Qu $\mathrm{J}$, Liu GH. Chemical screen identifies a geroprotective role of quercetin in premature aging. Protein Cell 2018 [PMID: 30069858 DOI: 10.1007/s13238-018-0567-y]

30 Hisamatsu D, Ohno-Oishi M, Nakamura S, Mabuchi Y, Naka-Kaneda H. Growth differentiation factor 6 derived from mesenchymal stem/stromal cells reduces age-related functional deterioration in multiple tissues. Aging (Albany NY) 2016; 8: 1259-1275 [PMID: 27311402 DOI: 10.18632/aging.100982]

31 Yin Y, Wu RX, He XT, Xu XY, Wang J, Chen FM. Influences of age-related changes in mesenchymal stem cells on macrophages during in-vitro culture. Stem Cell Res Ther 2017; 8: 153 [PMID: 28646912 DOI: 10.1186/s13287-017-0608-0]

32 Wang B, Lee WY, Huang B, Zhang JF, Wu T, Jiang X, Wang CC, Li G. Secretome of Human Fetal Mesenchymal Stem Cell Ameliorates Replicative Senescen. Stem Cells Dev 2016; 25: 1755-1766 [PMID: 27539404 DOI: 10.1089/scd.2016.0079]

33 Kim YJ, Seo DH, Lee SH, Lee SH, An GH, Ahn HJ, Kwon D, Seo KW, Kang KS. Conditioned media from human umbilical cord blood-derived mesenchymal stem cells stimulate rejuvenation function in human skin. Biochem Biophys Rep 2018; 16: 96-102 [PMID: 30417126 DOI: 10.1016/j.bbrep.2018.10.007]

34 Lei L, Su J, Chen J, Chen W, Chen X, Peng C. The role of lysophosphatidic acid in the physiology and pathology of the skin. Life Sci 2019; 220: 194-200 [PMID: 30584899 DOI: 10.1016/j.lfs.2018.12.040]

35 Kanehira M, Fujiwara T, Nakajima S, Okitsu Y, Onishi Y, Fukuhara N, Ichinohasama R, Okada Y, Harigae H. An Lysophosphatidic Acid Receptors 1 and 3 Axis Governs Cellular Senescence of Mesenchymal Stromal Cells and Promotes Growth and Vascularization of Multiple Myeloma. Stem Cells 2017; 35: 739-753 [PMID: 27641212 DOI: 10.1002/stem.2499]

36 Fan J, An X, Yang Y, Xu H, Fan L, Deng L, Li T, Weng X, Zhang J, Chunhua Zhao R. MiR-1292 Targets FZD4 to Regulate Senescence and Osteogenic Differentiation of Stem Cells in TE/SJ/Mesenchymal Tissue System via the Wnt/ $\beta$-catenin Pathway. Aging Dis 2018; 9: 1103-1121 [PMID: 30574422 DOI: 10.14336/AD.2018.1110]

37 Liu W, Qi M, Konermann A, Zhang L, Jin F, Jin Y. The p53/miR-17/Smurf1 pathway mediates skeletal deformities in an age-related model via inhibiting the function of mesenchymal stem cells. Aging (Albany NY) 2015; 7: 205-218 [PMID: 25855145 DOI: 10.18632/aging.100728]

38 Dong J, Zhang Z, Huang H, Mo P, Cheng C, Liu J, Huang W, Tian C, Zhang C, Li J. miR-10a rejuvenates aged human mesenchymal stem cells and improves heart function after myocardial infarction through KLF4. Stem Cell Res Ther 2018; 9: 151 [PMID: 29848383 DOI: 10.1186/s13287-018-0895-0]

39 Zhang T, Wang P, Liu Y, Zhou J, Shi Z, Cheng K, Huang T, Wang X, Yang GL, Yang B, Ma S, Guan F. Overexpression of FOXQ1 enhances anti-senescence and migration effects of human umbilical cord mesenchymal stem cells in vitro and in vivo. Cell Tissue Res 2018; 373: 379-393 [PMID: 29500491 DOI: 10.1007/s00441-018-2815-0]

40 Xu R, Fu Z, Liu X, Xiao T, Zhang P, Du Y, Yuan H, Cheng J, Jiang H. Transplantation of osteoporotic bone marrow stromal cells rejuvenated by the overexpression of SATB2 prevents alveolar bone loss in ovariectomized rats. Exp Gerontol 2016; 84: 71-79 [PMID: 27599698 DOI: 10.1016/j.exger.2016.09.001]

41 Roux C, Saviane G, Pini J, Belaïd N, Dhib G, Voha C, Ibáñez L, Boutin A, Mazure NM, Wakkach A, Blin-Wakkach C, Rouleau M. Immunosuppressive Mesenchymal Stromal Cells Derived from Human- 
Induced Pluripotent Stem Cells Induce Human Regulatory T Cells In Vitro and In Vivo. Front Immunol 2018; 8: 1991 [PMID: 29422893 DOI: 10.3389/fimmu.2017.01991]

42 Wang LT, Jiang SS, Ting CH, Hsu PJ, Chang CC, Sytwu HK, Liu KJ, Yen BL. Differentiation of Mesenchymal Stem Cells from Human Induced Pluripotent Stem Cells Results in Downregulation of cMyc and DNA Replication Pathways with Immunomodulation Toward CD4 and CD8 Cells. Stem Cells 2018; 36: 903-914 [PMID: 29396902 DOI: 10.1002/stem.2795]

43 Zheng Y, Lei Y, Hu C, Hu C. p53 regulates autophagic activity in senescent rat mesenchymal stromal cells. Exp Gerontol 2016; 75: 64-71 [PMID: 26792455 DOI: 10.1016/j.exger.2016.01.004]

44 Borodkina AV, Shatrova AN, Deryabin PI, Grukova AA, Nikolsky NN, Burova EB. Tetraploidization or autophagy: The ultimate fate of senescent human endometrial stem cells under ATM or p53 inhibition. Cell Cycle 2016; 15: 117-127 [PMID: 26636375 DOI: 10.1080/15384101.2015.1121326]

45 Falser N, Bandtlow I, Rziha HJ, Haus M, Wolf $\mathrm{H}$. The role of acute and latent virus infections in the pathogenesis of inner ear disturbances. Am J Otol 1987; 8: 136-147 [PMID: 3035932 DOI: 10.1016/S0196-0709(87)80034-0]

46 Brunk UT, Terman A. The mitochondrial-lysosomal axis theory of aging: accumulation of damaged mitochondria as a result of imperfect autophagocytosis. Eur J Biochem 2002; 269: 1996-2002 [PMID: 11985575 DOI: 10.1046/j.1432-1033.2002.02869.x]

47 Dicarlo M, Teti G, Iezzi I, Cerqueni G, Manzotti S, Falconi M, Mattioli-Belmonte M. Detecting senescent fate in mesenchymal stem cells: a combined cytofluorimetric and ultrastructural approach. Biogerontology 2018; 19: 401-414 [PMID: 30101381 DOI: 10.1007/s10522-018-9766-4]

48 Zecchini S, Giovarelli M, Perrotta C, Morisi F, Touvier T, Di Renzo I, Moscheni C, Bassi MT, Cervia D, Sandri M, Clementi E, De Palma C. Autophagy controls neonatal myogenesis by regulating the GH-IGF1 system through a NFE2L2- and DDIT3-mediated mechanism. Autophagy 2019; 15: 58-77 [PMID: 30081710 DOI: 10.1080/15548627.2018.1507439]

49 Capasso S, Alessio N, Squillaro T, Di Bernardo G, Melone MA, Cipollaro M, Peluso G, Galderisi U. Changes in autophagy, proteasome activity and metabolism to determine a specific signature for acute and chronic senescent mesenchymal stromal cells. Oncotarget 2015; 6: 39457-39468 [PMID: 26540573 DOI: 10.18632/oncotarget.6277]

50 Zhao K, Hao H, Liu J, Tong C, Cheng Y, Xie Z, Zang L, Mu Y, Han W. Bone marrow-derived mesenchymal stem cells ameliorate chronic high glucose-induced $\beta$-cell injury through modulation of autophagy. Cell Death Dis 2015; 6: e1885 [PMID: 26379190 DOI: 10.1038/cddis.2015.230]

51 Chang TC, Hsu MF, Wu KK. High glucose induces bone marrow-derived mesenchymal stem cell senescence by upregulating autophagy. PLoS One 2015; 10: e0126537 [PMID: 25961745 DOI: 10.1371/journal.pone.0126537]

52 Bárcena C, López-Otín C, Kroemer G. Methionine restriction for improving progeria: another autophagyinducing anti-aging strategy? Autophagy 2019; 15: 558-559 [PMID: 30304972 DOI: $10.1080 / 15548627.2018 .1533059]$

53 Alessio N, Del Gaudio S, Capasso S, Di Bernardo G, Cappabianca S, Cipollaro M, Peluso G, Galderisi U. Low dose radiation induced senescence of human mesenchymal stromal cells and impaired the autophagy process. Oncotarget 2015; 6: 8155-8166 [PMID: 25544750 DOI: 10.18632/oncotarget.2692]

54 Ma Y, Qi M, An Y, Zhang L, Yang R, Doro DH, Liu W, Jin Y. Autophagy controls mesenchymal stem cell properties and senescence during bone aging. Aging Cell 2018; 17 [PMID: 29210174 DOI: 10.1111/acel.12709]

55 Wan Y, Zhuo N, Li Y, Zhao W, Jiang D. Autophagy promotes osteogenic differentiation of human bone marrow mesenchymal stem cell derived from osteoporotic vertebrae. Biochem Biophys Res Commun 2017; 488: 46-52 [PMID: 28476617 DOI: 10.1016/j.bbrc.2017.05.004]

56 Squillaro T, Antonucci I, Alessio N, Esposito A, Cipollaro M, Melone MAB, Peluso G, Stuppia L, Galderisi U. Impact of lysosomal storage disorders on biology of mesenchymal stem cells: Evidences from in vitro silencing of glucocerebrosidase (GBA) and alpha-galactosidase A (GLA) enzymes. J Cell Physiol 2017; 232: 3454-3467 [PMID: 28098348 DOI: 10.1002/jcp.25807]

57 Wang L, Han X, Qu G, Su L, Zhao B, Miao J. A pH probe inhibits senescence in mesenchymal stem cells. Stem Cell Res Ther 2018; 9: 343 [PMID: 30526663 DOI: 10.1186/s13287-018-1081-0]

58 Yang M, Wen T, Chen H, Deng J, Yang C, Zhang Z. Knockdown of insulin-like growth factor 1 exerts a protective effect on hypoxic injury of aged BM-MSCs: role of autophagy. Stem Cell Res Ther 2018; 9: 284 [PMID: 30359321 DOI: 10.1186/s13287-018-1028-5]

59 Yun SP, Han YS, Lee JH, Kim SM, Lee SH. Melatonin Rescues Mesenchymal Stem Cells from Senescence Induced by the Uremic Toxin p-Cresol via Inhibiting mTOR-Dependent Autophagy. Biomol Ther (Seoul) 2018; 26: 389-398 [PMID: 28655071 DOI: 10.4062/biomolther.2017.071]

60 Denu RA, Hematti P. Effects of Oxidative Stress on Mesenchymal Stem Cell Biology. Oxid Med Cell Longev 2016; 2016: 2989076 [PMID: 27413419 DOI: 10.1155/2016/2989076]

61 Scialò F, Fernández-Ayala DJ, Sanz A. Role of Mitochondrial Reverse Electron Transport in ROS Signaling: Potential Roles in Health and Disease. Front Physiol 2017; 8: 428 [PMID: 28701960 DOI: 10.3389/fphys.2017.00428]

62 Marycz K, Kornicka K, Basinska K, Czyrek A. Equine Metabolic Syndrome Affects Viability, Senescence, and Stress Factors of Equine Adipose-Derived Mesenchymal Stromal Stem Cells: New Insight into EqASCs Isolated from EMS Horses in the Context of Their Aging. Oxid Med Cell Longev 2016; 2016: 4710326 [PMID: 26682006 DOI: 10.1155/2016/4710326]

63 Marycz K, Kornicka K, Marędziak M, Golonka P, Nicpoń J. Equine metabolic syndrome impairs adipose stem cells osteogenic differentiation by predominance of autophagy over selective mitophagy. J Cell Mol Med 2016; 20: 2384-2404 [PMID: 27629697 DOI: 10.1111/jcmm.12932]

64 Deschênes-Simard X, Parisotto M, Rowell MC, Le Calvé B, Igelmann S, Moineau-Vallée K, SaintGermain E, Kalegari P, Bourdeau V, Kottakis F, Bardeesy N, Ferbeyre G. Circumventing senescence is associated with stem cell properties and metformin sensitivity. Aging Cell 2019; 18: e12889 [PMID: 30614183 DOI: 10.1111/acel.12889]

65 Khanh VC, Zulkifli AF, Tokunaga C, Yamashita T, Hiramatsu Y, Ohneda O. Aging impairs beige adipocyte differentiation of mesenchymal stem cells via the reduced expression of Sirtuin 1. Biochem Biophys Res Commun 2018; 500: 682-690 [PMID: 29678576 DOI: 10.1016/j.bbrc.2018.04.136]

66 Huang T, Liu R, Fu X, Yao D, Yang M, Liu Q, Lu WW, Wu C, Guan M. Aging Reduces an ERRalphaDirected Mitochondrial Glutaminase Expression Suppressing Glutamine Anaplerosis and Osteogenic Differentiation of Mesenchymal Stem Cells. Stem Cells 2017; 35: 411-424 [PMID: 27501743 DOI: 10.1002/stem.2470] 
67 Shuai Y, Liao L, Su X, Yu Y, Shao B, Jing H, Zhang X, Deng Z, Jin Y. Melatonin Treatment Improves Mesenchymal Stem Cells Therapy by Preserving Stemness during Long-term In Vitro Expansion. Theranostics 2016; 6: 1899-1917 [PMID: 27570559 DOI: 10.7150/thno.15412]

68 Fang J, Yan Y, Teng X, Wen X, Li N, Peng S, Liu W, Donadeu FX, Zhao S, Hua J. Melatonin prevents senescence of canine adipose-derived mesenchymal stem cells through activating NRF2 and inhibiting ER stress. Aging (Albany NY) 2018; 10: 2954-2972 [PMID: 30362962 DOI: 10.18632/aging. 101602]

69 Xie Z, Jones A, Deeney JT, Hur SK, Bankaitis VA. Inborn Errors of Long-Chain Fatty Acid $\beta$-Oxidation Link Neural Stem Cell Self-Renewal to Autism. Cell Rep 2016; 14: 991-999 [PMID: 26832401 DOI: 10.1016/j.celrep.2016.01.004]

70 Farahzadi R, Fathi E, Mesbah-Namin SA, Zarghami N. Anti-aging protective effect of L-carnitine as clinical agent in regenerative medicine through increasing telomerase activity and change in the hTERT promoter CpG island methylation status of adipose tissue-derived mesenchymal stem cells. Tissue Cell 2018; 54: 105-113 [PMID: 30309499 DOI: 10.1016/j.tice.2018.08.012]

71 Oh JY, Choi GE, Lee HJ, Jung YH, Chae CW, Kim JS, Lee CK, Han HJ. 17ß-Estradiol protects mesenchymal stem cells against high glucose-induced mitochondrial oxidants production via Nrf2/Sirt3/MnSOD signaling. Free Radic Biol Med 2019; 130: 328-342 [PMID: 30412732 DOI: 10.1016/j.freeradbiomed.2018.11.003]

72 Denu RA. SIRT3 Enhances Mesenchymal Stem Cell Longevity and Differentiation. Oxid Med Cell Longev 2017; 2017: 5841716 [PMID: 28717408 DOI: 10.1155/2017/5841716]

73 Lombard DB, Alt FW, Cheng HL, Bunkenborg J, Streeper RS, Mostoslavsky R, Kim J, Yancopoulos G, Valenzuela D, Murphy A, Yang Y, Chen Y, Hirschey MD, Bronson RT, Haigis M, Guarente LP, Farese RV, Weissman S, Verdin E, Schwer B. Mammalian Sir2 homolog SIRT3 regulates global mitochondrial lysine acetylation. Mol Cell Biol 2007; 27: 8807-8814 [PMID: 17923681 DOI: 10.1128/MCB.01636-07]

74 Yao J, Zheng J, Cai J, Zeng K, Zhou C, Zhang J, Li S, Li H, Chen L, He L, Chen H, Fu H, Zhang Q, Chen G, Yang Y, Zhang Y. Extracellular vesicles derived from human umbilical cord mesenchymal stem cells alleviate rat hepatic ischemia-reperfusion injury by suppressing oxidative stress and neutrophil inflammatory response. FASEB J 2019; 33: 1695-1710 [PMID: 30226809 DOI: 10.1096/fj.201800131RR]

75 Tofiño-Vian M, Guillén MI, Pérez Del Caz MD, Castejón MA, Alcaraz MJ. Extracellular Vesicles from Adipose-Derived Mesenchymal Stem Cells Downregulate Senescence Features in Osteoarthritic Osteoblasts. Oxid Med Cell Longev 2017; 2017: 7197598 [PMID: 29230269 DOI: 10.1155/2017/7197598]

76 Xu M, Bradley EW, Weivoda MM, Hwang SM, Pirtskhalava T, Decklever T, Curran GL, Ogrodnik M, Jurk D, Johnson KO, Lowe V, Tchkonia T, Westendorf JJ, Kirkland JL. Transplanted Senescent Cells Induce an Osteoarthritis-Like Condition in Mice. J Gerontol A Biol Sci Med Sci 2017; 72: 780-785 [PMID: 27516624 DOI: 10.1093/gerona/glw154]

77 McCulloch K, Litherland GJ, Rai TS. Cellular senescence in osteoarthritis pathology. Aging Cell 2017; 16: 210-218 [PMID: 28124466 DOI: 10.1111/acel.12562]

78 Platas J, Guillén MI, Pérez Del Caz MD, Gomar F, Castejón MA, Mirabet V, Alcaraz MJ. Paracrine effects of human adipose-derived mesenchymal stem cells in inflammatory stress-induced senescence features of osteoarthritic chondrocytes. Aging (Albany NY) 2016; 8: 1703-1717 [PMID: 27490266 DOI: 10.18632/aging.101007]

79 Bebelman MP, Smit MJ, Pegtel DM, Baglio SR. Biogenesis and function of extracellular vesicles in cancer. Pharmacol Ther 2018; 188: 1-11 [PMID: 29476772 DOI: 10.1016/j.pharmthera.2018.02.013]

80 Phinney DG, Pittenger MF. Concise Review: MSC-Derived Exosomes for Cell-Free Therapy. Stem Cells 2017; 35: 851-858 [PMID: 28294454 DOI: 10.1002/stem.2575]

81 Lin S, Zhu B, Huang G, Zeng Q, Wang C. Microvesicles derived from human bone marrow mesenchymal stem cells promote U2OS cell growth under hypoxia: the role of PI3K/AKT and HIF-1 $\alpha$. Hum Cell 2019; 32: 64-74 [PMID: 30506278 DOI: 10.1007/s13577-018-0224-Z]

82 Zhu Z, Zhang Y, Zhang Y, Zhang H, Liu W, Zhang N, Zhang X, Zhou G, Wu L, Hua K, Ding J. Exosomes derived from human umbilical cord mesenchymal stem cells accelerate growth of VK2 vaginal epithelial cells through MicroRNAs in vitro. Hum Reprod 2019; 34: 248-260 [PMID: 30576496 DOI: 10.1093/humrep/dey344]

83 Kulkarni R, Bajaj M, Ghode S, Jalnapurkar S, Limaye L, Kale VP. Intercellular Transfer of Microvesicles from Young Mesenchymal Stromal Cells Rejuvenates Aged Murine Hematopoietic Stem Cells. Stem Cells 2018; 36: 420-433 [PMID: 29230885 DOI: 10.1002/stem.2756]

84 Khayrullin A, Krishnan P, Martinez-Nater L, Mendhe B, Fulzele S, Liu Y, Mattison JA, Hamrick MW. Very Long-Chain C24:1 Ceramide Is Increased in Serum Extracellular Vesicles with Aging and Can Induce Senescence in Bone-Derived Mesenchymal Stem Cells. Cells 2019; 8: pii: E37 [PMID: 30634626 DOI: $10.3390 /$ cells 8010037 ] 


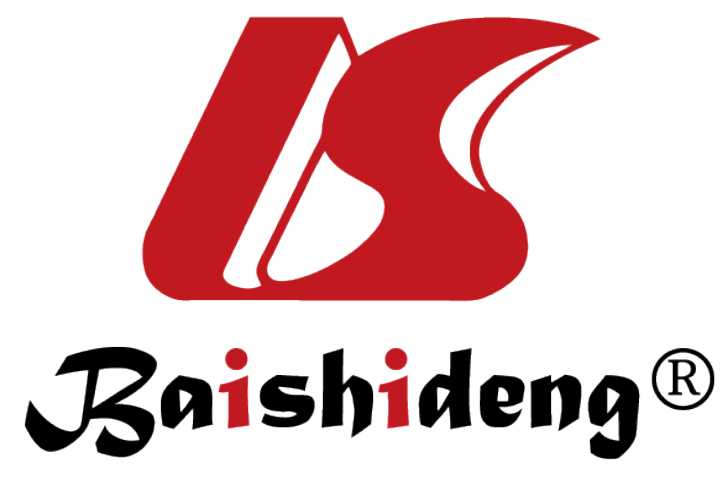

Published By Baishideng Publishing Group Inc

7041 Koll Center Parkway, Suite 160, Pleasanton, CA 94566, USA

Telephone: +1-925-2238242

Fax: +1-925-2238243

E-mail: bpgoffice@wjgnet.com

Help Desk: https://www.f6publishing.com/helpdesk

https://www.wjgnet.com

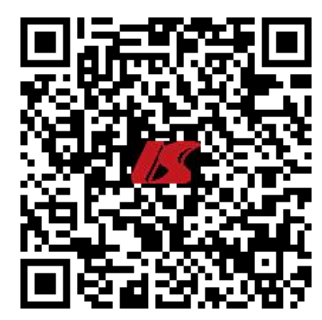

